\title{
Angelman syndrome (AS, MIM 105830)
}

Angelman syndrome (AS) is a distinct neurogenetic syndrome, first described in 1965 . The phenotype is well known in infancy and adulthood, but the clinical features may change with age. The main clinical characteristics include severe mental retardation, epileptic seizures and EEG abnormalilties, neurological problems and distinct facial dysmorphic features. Behavioural problems such as hyperactivity and sleeping problems are reported, although these patients present mostly a happy personality with periods of inappropriate laughter. Different underlying genetic mechanisms may cause AS, with deletion of chromosome 15 as the most frequent cause. Other genetic mechanisms such as paternal uniparental disomy, imprinting defect and mutation in the UBE3A gene are present in smaller groups of patients with AS. As the recurrence risk can be up to $50 \%$, the clinical diagnosis of AS should be confirmed by laboratory tesing, and genetic counselling should be provided. Treatment of seizures, physical therapy or other intervention strategies are helpful to ameliorate the symptoms.

\section{In brief}

- Angelman syndrome (AS) is characterised by severe mental retardation, absent speech, dysmorphic facial features, microcephaly, epileptic seizures, EEG abnormalities and neurological problems.

- The behavioural phenotype includes hyperactivity, sleeping problems, happy personality and periods of inappropriate laughter.
- Different genetic mechanisms may cause AS, such as deletion of the 15q11.2-q13 critical region (60-75\%), paternal uniparental disomy (2-5\%), imprinting defect $(2-5 \%)$ and mutation in the UBE3A gene $(10 \%)$.

- Genetic counselling is advised as the recurrence varies between 0 and $50 \%$, depending on the underlying genetic mechanism.

- Management is symptomatic: treatment of seizures, physical therapy or other intervention strategies.

\section{Introduction}

Angelman syndrome (AS) is a distinct neurogenetic syndrome, first described by Dr Harry Angelman in 1965, an English paediatrician, who described three severely mentally retarded children. AS presents with severe mental retardation, absent speech, periods of inappropriate laughter, microcephaly, macrostomia, maxillary hypoplasia, prognathia and neurological problems with a puppet-like gait, ataxia and epileptic seizures with specific EEG

Griet Van Buggenhout ${ }^{*, 1}$ and Jean-Pierre Fryns ${ }^{1}$

${ }^{1}$ Centre for Human Genetics, University Hospital Leuven, Leuven, Belgium

European Journal of Human Genetics (2009) 17, 1367-1373; doi:10.1038/ ejhg.2009.67; published online 20 May 2009

Keywords: Angelman syndrome; 15q11.2-q13 deletion; paternal UPD; UBE $3 A$ gene; imprinting centre defect

*Correspondence: Dr G Van Buggenhout, Center for Human Genetics, University Hospital Gasthuisberg, Herestraat 49, Leuven 3000, Belgium. Tel: + 3216 345; Fax: + 3216346 051;

E-mail: Griet.VanBuggenhout@uzleuven.be

Received 3 September 2008; revised 15 January 2009; accepted 22 January 2009; published online 20 May 2009 abnormalities. ${ }^{1}$ Patients have a happy and excitable personality. With advancing age, the typical phenotype becomes less striking because of the facial coarsening, thoracic scoliosis and mobility problems. Seizures remain present in adult AS patients, but hyperactivity, short attention span and sleeping problems improve in adulthood. $^{2-4}$ The incidence of AS is estimated to be between $1 / 10000$ and $1 / 20000 .^{5}$ Different genetic mechanisms may cause AS, such as deletion of the 15q11.2-q13 critical region (60-75\%), paternal uniparental disomy (UPD) $(2-5 \%)$, mutations in the imprinting centre $(2-5 \%)$ and mutation in the $U B E 3 A$ gene $(10 \%)$. In a group of $5-26 \%$ patients the diagnosis of AS is pure clinical and no genetic cause is found, although the recurrence risk can be as high as $50 \%$.

\section{Clinical overview}

In the newborn baby the phenotype seems to be normal. In the first 6 months of the neonatal period, feeding problems and muscle hypotonia may be present. ${ }^{5}$ At the age of 6 months there is a developmental delay. The diagnosis of AS is often difficult to suspect in infancy as developmental delay, hypotonia and other non-specific features usually 

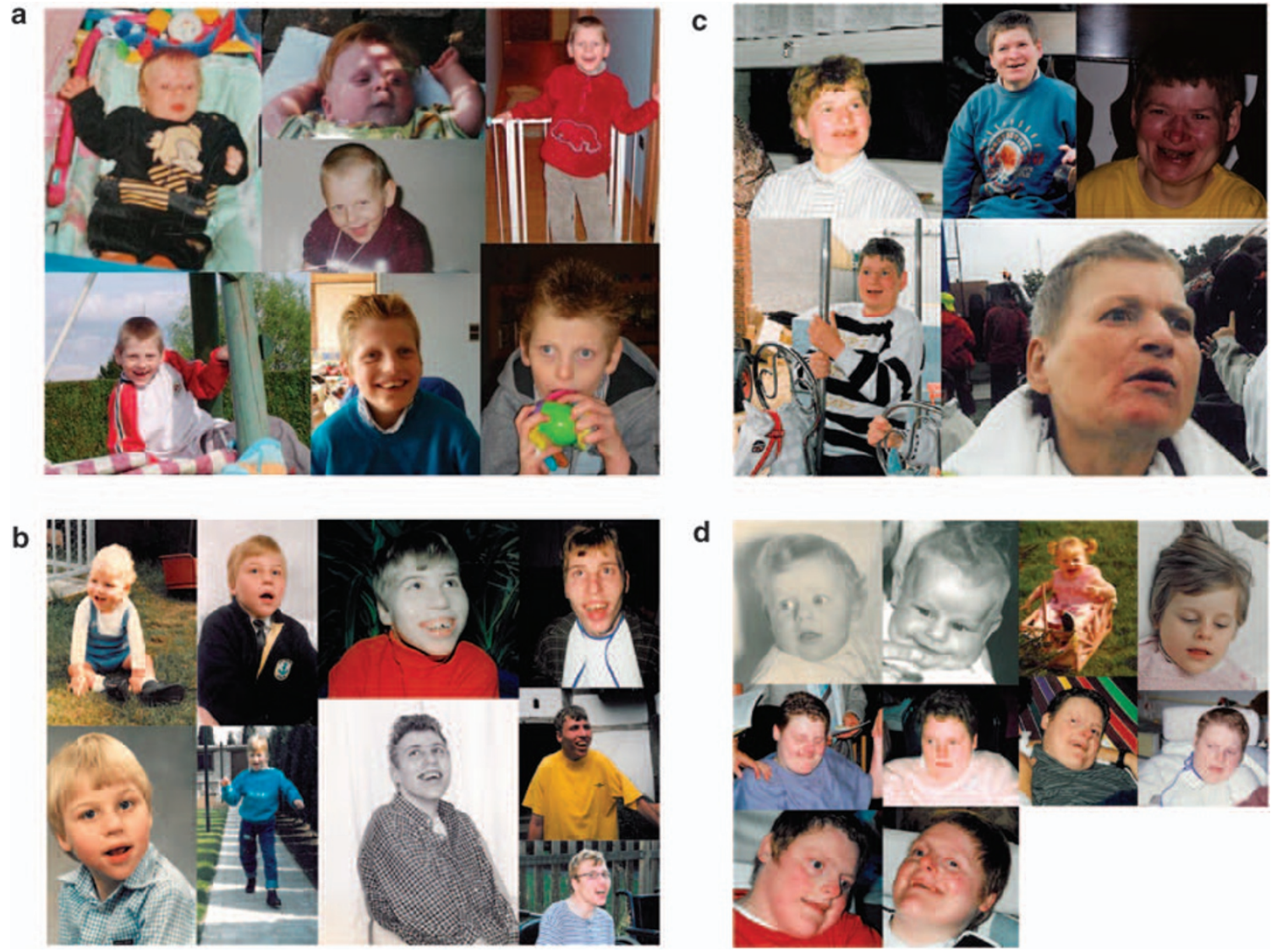

Figure 1 (a-d) Four AS patients at different ages presenting the typical facial dysmorphic features: round face, microcephaly and happy personality.

emerge between 6 months and 2 years of age. However, the presence of tremulous movements or unsteady movements before walking may suggest the diagnosis of AS. From the age of 1 year, the typical features of AS become more clear such as severe mental retardation, absent speech, outbursts of laughter, microcephaly, macrostomia, maxillary hypoplasia, prognathia and neurological problems with a puppet-like gait, ataxia and epileptic seizures with specific EEG abnormalities. In childhood, a diversity of seizures was observed, such as tonic-clonic seizures, atypical absence seizures, myoclonic seizures, status epilepticus and absence status, and myoclonic status. ${ }^{6,7}$ The most typical EEG finding in AS in children and adults is the presence of triphasic delta activity with a maximum over the frontal regions. The probability of having these triphasic waves increases with age and this EEG pattern can be helpful for making the diagnosis of AS in mentally retarded patients. ${ }^{1}$

The behavioural phenotype in these patients include a happy personality, there are outbursts of laughter often with hand flapping, hyperactivity without aggression, short attention span, excitability and sleeping problems with decreased need to sleep, increased sensitivity to heat, attraction to and fascination with water. ${ }^{1-4,8}$

Addendum 1 presents an overview of the recently updated diagnostic criteria (developmental, laboratory and clinical features) according to the Scientific Advisory Committee of the US Angelman Syndrome Foundation. ${ }^{1}$ Figure 1 presents several AS patients at different ages.

\section{Long-term follow-up and complications}

Life expectancy in AS seems to be nearly normal, but there are no data available. With advancing age the clinical picture may change and marked prognathism, macrostomia and prominent lower lip can be noted in adult AS patients, especially in those with increased mouthing behaviours and tongue protrusion and can be present both in patients with and without anti-epileptic drug treatment. About $90 \%$ of patients develop seizures at the first year of age. Although several authors ${ }^{2,9,10}$ reported a decrease of the epileptic seizures in adulthood, Laan et $\mathrm{al}^{7}$ observed that $92 \%$ of the adult patients still experienced epileptic 
seizures, with atypical absence seizures and myoclonic seizures being the most prominent.

Most AS patients have a stable vision without any type of degenerative retinopathy, although iris and choroidal hypopigmentation is to be expected in patients with a deletion of the 15q11.2-q13 critical region. Strabismus, optical nerve atrophy and blindness are rarely reported. ${ }^{11,12}$

Thoracic scoliosis is reported in about $40 \%$ of the adults and mostly in females. ${ }^{13}$

Vagal hypertonia resulting in cardiac rhythm disturbances is reported, and should be considered in the anaesthetic and perioperative care of AS patients. ${ }^{14,15}$

With advancing age adults become less active and there is a tendency towards obesity. Mobility decreases with joint contractures leading to difficulties of walking and some patients become wheelchair bound. ${ }^{16}$

\section{Management}

The use of special nipples may improve feeding in newborn AS babies with feeding difficulties. Gastroesophageal reflux is often present and requires upright positioning or specific motility medications. As the majority of the patients develop seizures at very young age early attention should be given to this possible complication, which needs anticonvulsant medications. As children may develop ocular problems, visual assessment is important to encourage interactions and diminish autistic and selfmutilative tendencies. ${ }^{17}$ Ocular surgery can be offered in patients with strabismus. A diet rich to fibers or laxative agents can be helpful in patients with constipation. Drooling in mentally retarded patients is often present but difficult to treat, and behavioural treatment should be considered. ${ }^{18}$ New surgical techniques on salivary duct reimplantation or ligation in this improving treatment area are valuable alternatives. In only one AS patient specific dental treatment was reported by Murakami et al. ${ }^{19}$ Orthopedic problems, such as subluxed or pronated ankles, tight Achilles tendons or scoliosis may be treated by bracing or even surgery. Vigilance of cardiac rhythm during anaesthesia and perioperative period is required. ${ }^{14,15}$

Physical therapy is needed for the unstable or nonambulatory children and for extremely atactic children adaptive chairs or positioners. With advancing age, adults become less active and the use of activity schedules may be helpful to prevent the extent of scoliosis and obesity. As decreased mobility leading to the difficulties of walking, prevention should be focused on the severe neurological instability by providing rehabilitative, early intervention and psychosocial services. ${ }^{17}$ Occupational therapy is needed to stimulate fine motor and oral-motor control skills. Speech therapy including nonverbal methods of communication, picture cards or communication boards should be introduced as active communication in this group of children is poorly developed.
Patients with excessive hypermotoric behaviour need a safe and adapted environment or may be treated with medication, but often patients benefit from both options. Sedative medication can be given in case of severe sleep problems. Melatonin may promote sleep in AS patients, but Braam et al $^{20}$ observed that melatonin lost its beneficial effect after several weeks in most AS patients.

\section{Differential diagnosis}

Owing to the presence of spastic paraplegia, the diagnosis of perinatal damage is often considered. In this group of mentally retarded patients, the typical EEG pattern can be helpful for the diagnosis of AS and differential diagnosis includes hypsarrhythmia in the West syndrome or the petit mal variant pattern in Lennox-Gastaut.

A portion of children with a clinical diagnosis of AS but without genetic confirmation, have mutations in the MECP2 gene confirming Rett syndrome. ${ }^{21}$ Certainly in the first few years of life Rett syndrome should be suspected in these AS-test negative girls.

Mowat-Wilson syndrome is caused by heterozygous deletions or truncating mutations in the ZFHX1B (SIP1) gene on $2 \mathrm{q} 22$. The facial features, severe mental retardation, microcephaly, seizures and short stature are resembling the AS. ${ }^{22}$

$\mathrm{X}$-linked alpha-thalassemia/mental retardation syndrome (ATR-X) is caused by mutations in the XNP gene on Xq13. These patients have severe mental retardation, there is no speech development and seizures are common. ${ }^{23}$

The 22q13 deletion syndrome (Phelan-McDermid syndrome) with variable sizes of the deletion are often submicroscopic and requires special molecular cytogenetic methods to detect the deletion. Patients have global developmental delay, moderate to profound mental retardation, delay of speech development and mild dysmorphic features. ${ }^{24}$

Many microdeletions, with a wide spectrum of clinical features, can mimic the features of AS and the value of comparative genome hybridisation (CGH) is therefore a valuable tool in AS-test negative patients.

\section{Genetic basis of AS}

Different underlying genetic mechanisms may cause AS resulting in a comparable clinical phenotype with severe mental retardation, speech retardation and behavioural phenotype. However, differences in the clinical phenotype are observed in AS patients, with a different underlying genetic mechanism. $^{25}$

A deletion or re-arrangement of the maternal chromosome 15 at locus $15 q 11-q 13$ is present in $60-75 \%$ of the patients. Patients with a deletion have a more severe clinical phenotype including microcephaly, motor difficulties, seizures and language impairment. ${ }^{1,26,27}$ 
A small percentage of patients $(2-5 \%)$ have paternal UPD for chromosome $15 .^{28}$ The UPD can be composed by both homologous chromosomes from one parent (heterodisomy) or by a duplication of one chromosome (isodisomy), or by a mixture of both these chromosomal compositions. ${ }^{29}$ Mechanisms of UPD formation are trisomy rescue, gamete complementation, mitotic duplication and post-fertilization errors. ${ }^{30}$ The mechanism of paternal UPD of chromosome 15 was described by Robinson et al, ${ }^{31}$ showing a somatic segregation error in about $75 \%$ of these paternal UPD15 cases. A milder clinical phenotype in patients with paternal UPD has been suggested compared with AS patients with a deletion. ${ }^{32,33}$ This group of patients has less frequent microcephaly, motor and ataxia problems and seizures. ${ }^{1}$

Mutations in the imprinting centre (IC) (imprinting centre defect) are present in about $2-5 \%$ of the patients. Microcephaly, hypopigmentation, motor and ataxia problems and seizures are less frequent in this group of patients. ${ }^{1,34}$ Some patients have more advanced speech abilities. $^{35}$

The PWS/AS region contains a number of genes that are expressed exclusively from the paternal chromosome 15 (eg MKRN3, MAGEL2, NDN, SNURF-SNRPN, C15orf2 and PWRN1) or maternal chromosome 15 (eg UBE3A, ATP1OA). Mutations in the $U B E 3 A$ gene were first described in 1997 by Kishino et $a l^{36}$ and Matsuura et $a l^{37}$ and are present in about $10 \%$ of the patients. The cardinal features of AS are caused by deficient expression or function of the maternally inherited $U B E 3 A$ allele in certain brain regions. ${ }^{13,38,39}$ Williams ${ }^{5}$ described the map of the $15 q 11.2-15 q 13$ region showing the complex mechanism of controlling the transcription of the $U B E 3 A$ gene by a distant imprinting control centre. The UBE3A gene shows biallellic expression in most tissues, but shows preferential expression of the maternal allele in the brain of humans and mice. ${ }^{40}$ The UBE3A gene produces the E6-associated protein (E6AP). This protein is acting as a cellular ligase enzyme to create a covalent linkage between the ubiquitin molecule and its target protein, which becomes polyubiquilated, and results finally in their degradation by the $26 \mathrm{~S}$ proteasome, and plays thus a role in cellular protein homeostasis. Mutations in the UBE3A gene results in a disrupted functioning of the protein and could cause the mental retardation and seizures. ${ }^{5}$

In a group of $5-26 \%$ of the patients with the classical phenotypic AS features, the genetic defect remains unidentified.

\section{Diagnostic approaches}

The diagnosis of AS is a clinical diagnosis confirmed by laboratory testing (Figure 2).

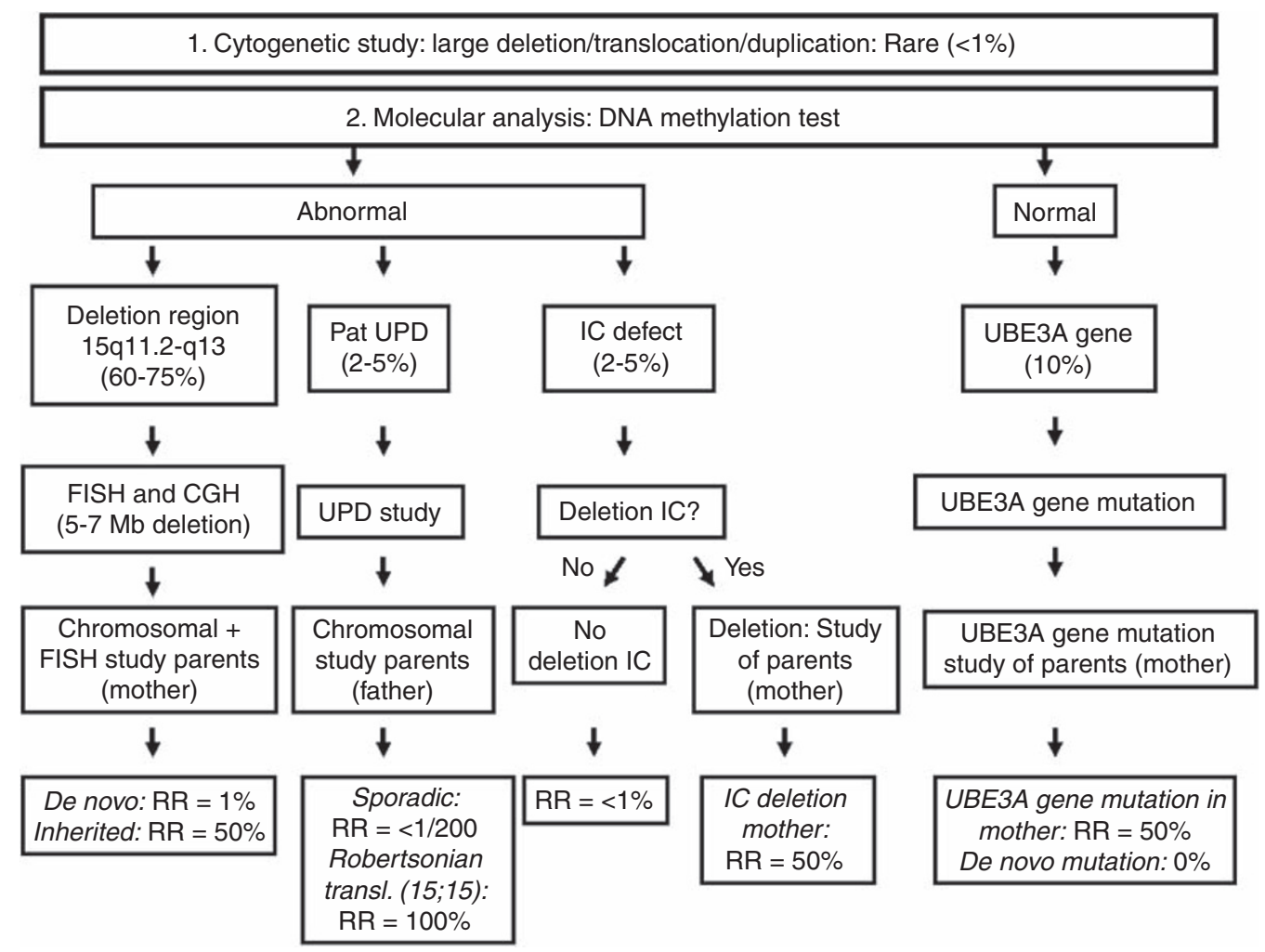

Figure 2 Diagram on diagnostic approach and recurrence risk. UPD, uniparental disomy; IC, imprinting centre; RR, recurrence risk. 
Cytogenetic approach A cytogenetically visible chromosome rearrangement involving the $15 q 11.2$-q13 region on a standard chromosomal analysis such as large deletion, translocation or inversion is seen in $<1 \%$ of the patients, but the $5-7 \mathrm{Mb}$ common deletion is not detected by routine chromosome analysis.

Molecular testing The DNA methylation test detects a deletion, UPD or an imprinting centre defect and confirms the diagnosis in about $78 \%$ of the patients. In addition, fluorescent in situ hybridisation studies (FISH) with the D15S10 and/or SNRPN probe detects a 4-6Mb deletion of the $15 q 11.2$-q13 region in about $70 \%(60-75 \%)$ of the patients. An alternative method to detect a (smaller) deletion may be CGH.

Sequence analysis of the $U B E 3 A$ gene detects mutations in about $10 \%$ of the patients.

In the remaining group of patients no further diagnostic approach is possible at this moment.

\section{Genetic counselling}

The recurrence risk of AS in subsequent children in families with a child with a de novo deletion is estimated $\sim 1 \%$. ${ }^{41}$ Kokkonen and Leisti ${ }^{42}$ reported two sibs who had an identical interstitial deletion in the maternal chromosome 5 suggesting the presence of germline mosaicism of del (15)(q11q13) in the mother.

In AS patients with a chromosomal rearrangement or small-inherited interstitial deletion the recurrence risk can be as high as 50\%. Therefore, chromosomal and FISH analyses should be performed in the parents (mother) of an AS patient with a deletion, to rule out a chromosomal rearrangement in the parents and to determine whether the rearrangement is inherited or de novo in the AS patient.

Paternal UPD of chromosome 15 arises as a sporadic event with an extremely low, probably $<1 / 200$, recurrence risk. A chromosomal analysis, however, is indicated in an AS patient with a UPD, to rule out an inherited paternal $15 ; 15$ Robertsonian translocation, as the recurrence risk can be very high (almost 100\%) in case the father is carrier of a $15 ; 15$ Robertsonian translocation.

The risk to subsequent children in case of an AS patient with an IC defect can be as high as $50 \%$. A patient with a deletion in the IC can have a phenotypically normal mother who also has an IC deletion, inherited from her father or acquired by a spontaneous mutation on her paternal chromosome 15, and in this situation the recurrence risk is $50 \% .{ }^{43}$ The recurrence risk in patients with an imprinting centre defect without a deletion, probably as the result of a de novo defect of the imprinting process during the oogenesis of the mother, is estimated $<1 \%$, and this is the case in $80 \%$ of patients with an IC defect. ${ }^{44}$

In $10 \%$ of the AS patients, a UBE3A gene mutation is present and can be de novo or inherited..$^{37,39}$ Females carrying a UBE3A gene mutation, without having AS because the gene is silenced, have a recurrence risk of $50 \%$ for a child with AS in each pregnancy. In case of a de novo UBE3A gene mutation in the proband, the recurrence risk is nearly $0 \%$. However, germline mosaicism was described in several families with affected siblings but without a mutation in the mother. ${ }^{45}$

In the remaining group of patients without a proven genetic defect the recurrence risk remains undetermined but may be high (up to 50\%) (see also Figure 2).

\section{References}

1 Williams CA, Beaudet AL, Clayton-Smith J et al: Angelman syndrome 2005: updated consensus for diagnostic criteria. Am J Med Genet A 2006; 140: 413-418.

2 Clayton-Smith J: Clinical research on Angelman syndrome in the United Kingdom: observations on 82 affected individuals. Am J Med Genet 1993; 46: 12-15.

3 Williams CA, Angelman H, Clayton-Smith J et al: Angelman syndrome: consensus for diagnostic criteria. Angelman Syndrome Foundation. Am J Med Genet 1995; 56: 237-238.

4 Zori RT, Hendrickson J, Woolven S, Whidden EM, Gray B, Williams CA: Angelman syndrome: clinical profile. J Child Neurol 1992; 7: 270-280.

5 Williams CA: Neurological aspects of the Angelman syndrome. Brain Dev 2005; 27: 88-94.

6 Guerrini R, De Lorey TM, Bonanni P et al: Cortical myoclonus in Angelman syndrome. Ann Neurol 1996; 40: 39-48.

7 Laan LA, Renier WO, Arts WF et al: Evolution of epilepsy and EEG findings in Angelman syndrome. Epilepsia 1997; 38: 195-199.

8 Descheemaeker M-J, Fryns JP: Spreken zonder taal: het syndroom van Angelman. Nederlands Tijdschrift voor de Zorg aan Verstandelijke Gehandicapten 1999; 25: 102-115.

9 Matsumoto A, Kumagai T, Miura K, Miyazaki S, Hayakawa C, Yamanaka T: Epilepsy in Angelman syndrome associated with chromosome 15q deletion. Epilepsia 1992; 33: 1083-1090.

10 Viani F, Romeo A, Viri $\mathrm{M}$ et al: Seizure and EEG patterns in Angelman's syndrome. J Child Neurol 1995; 10: 467-471.

11 Mah ML, Wallace DK, Powell CM: Ophthalmic manifestations of Angelman syndrome. J AAPOS 2000; 4: 248-249.

12 Rufa A, Dotti MT, Orrico A, Battisti C, Carletto F, Federico A: Retinochoroidal atrophy in two adult patients with Angelman syndrome. Am J Med Genet A 2003; 122A: 155-158.

13 Clayton-Smith J, Laan L: Angelman syndrome: a review of the clinical and genetic aspects. J Med Genet 2003; 40: 87-95.

14 Gardner JC, Turner CS, Ririe DG: Vagal hypertonia and anesthesia in Angelman syndrome. Paediatr Anaesth 2008; 18: 348-349.

15 Vanagt WY, Pulles-Heintzberger CF, Vernooy K, Cornelussen RN, Delhaas T: Asystole during outbursts of laughing in a child with Angelman syndrome. Pediatr Cardiol 2005; 26: 866-868.

16 Van Buggenhout GJ, Descheemaeker MJ, Thiry P, Trommelen JC, Hamel BC, Fryns JP: Angelman syndrome in three adult patients with atypical presentation and severe neurological complications. Genet Couns 2000; 11: 363-373.

17 Wilson GN, Cooley WC: Preventive Management of Children with Congenital Anomalies and Syndromes. Cambridge University Press: Cambridge, UK, 2000.

18 Van der Burg JJ, Didden R, Jongerius PH, Rotteveel JJ: Behavioral treatment of drooling: a methodological critique of the literature with clinical guidelines and suggestions for future research. Behav Modif 2007; 31: 573-594.

19 Murakami C, Nahas Pires Correa MS, Nahas Pires CF, Nahas Pires Correa JP: Dental treatment of children with Angelman syndrome: a case report. Spec Care Dentist 2008; 28: 8-11. 
20 Braam W, Smits MG, Didden R, Curfs LMG: Melatonin is effective in treating sleep problems in Angelman syndrome but problems in metabolising melatonin may be part of the Angelman phenotype. J Intellect Disabil Res 2008; 52: 814.

21 Jedele KB: The overlapping spectrum of Rett and Angelman syndromes: a clinical review. Semin Pediatr Neurol 2007; 14: $108-117$

22 Garavelli L, Mainardi PC: Mowat-Wilson syndrome. Orphanet J Rare Dis 2007; 2: 42.

23 Gibbons RJ, Higgs DR: Molecular-clinical spectrum of the ATR-X syndrome. Am J Med Genet 2000; 97: 204-212.

24 Phelan MC: Deletion 22q13.3 syndrome. Orphanet J Rare Dis 2008; 3: 14 .

25 Cassidy SB, Dykens E, Williams CA: Prader-Willi and Angelman syndromes: sister imprinted disorders. Am J Med Genet 2000; 97: $136-146$.

26 Moncla A, Malzac P, Livet MO et al: Angelman syndrome resulting from UBE3A mutations in 14 patients from eight families: clinical manifestations and genetic counselling. $J$ Med Genet 1999; 36: 554-560.

27 Smith A, Wiles C, Haan E et al: Clinical features in 27 patients with Angelman syndrome resulting from DNA deletion. I Med Genet 1996; 33: 107-112.

28 Knoll JH, Glatt KA, Nicholls RD, Malcolm S, Lalande M: Chromosome 15 uniparental disomy is not frequent in Angelman syndrome. Am J Hum Genet 1991; 48: 16-21.

29 Giardina E, Peconi C, Cascella R, Sinibaldi C, Nardone AM, Novelli G: A multiplex molecular assay for the detection of uniparental disomy for human chromosome 15. Electrophoresis 2008; 29: 4775-4779.

30 Kotzot D: Complex and segmental uniparental disomy (UPD): review and lessons from rare chromosomal complements. $J$ Med Genet 2001; 38: 497-507.

31 Robinson WP, Christian SL, Kuchinka BD et al: Somatic segregation errors predominantly contribute to the gain or loss of a paternal chromosome leading to uniparental disomy for chromosome 15. Clin Genet 2000; 57: 349-358.

32 Bottani A, Robinson WP, DeLozier-Blanchet CD et al: Angelman syndrome due to paternal uniparental disomy of chromosome 15: a milder phenotype? Am J Med Genet 1994; 51: 35-40.

\section{Addendum 1}

\section{Diagnostic criteria according to the Scientific Advisory Committee of the US Angelman syndrome Foundation (Williams et al 2006)}

\section{Developmental history and laboratory findings:}

(1) Normal prenatal and birth history with normal head circumference and absence of major birth defects. Feeding difficulties may be present in the neonate and infant.

(2) Developmental delay evident by 6-12 months of age, sometimes associated with truncal hypotonus. Unsteady limb movements and/or increased smiling may be evident.

(3) Delayed but forward progression of development (no loss of skills).

(4) Normal metabolical, hematological and chemical laboratory profiles.

(5) Structurally normal brain using MRI or CT (may have mild cortical atrophy or dysmyelination).
33 Smith A, Marks R, Haan E, Dixon J, Trent RJ: Clinical features in four patients with Angelman syndrome resulting from paternal uniparental disomy. J Med Genet 1997; 34: 426-429.

34 Saitoh S, Buiting K, Cassidy SB et al: Clinical spectrum and molecular diagnosis of Angelman and Prader-Willi syndrome patients with an imprinting mutation. Am J Med Genet 1997; 68: $195-206$.

35 Nazlican H, Zeschnigk M, Claussen U et al: Somatic mosaicism in patients with Angelman syndrome and an imprinting defect. Hum Mol Genet 2004; 13: 2547-2555.

36 Kishino T, Lalande M, Wagstaff J: UBE3A/E6-AP mutations cause Angelman syndrome. Nat Genet 1997; 15: 70-73. Erratum in Nat Genet 1997; 77: 54-59.

37 Matsuura T, Sutcliffe JS, Fang $\mathrm{P}$ et al: De novo truncating mutations in E6-AP ubiquitin-protein ligase gene (UBE3A) in Angelman syndrome. Nat Genet 1997; 15: 74-77.

38 Jiang Y, Lev-Lehman E, Bressler J, Tsai TF, Beaudet AL: Genetics of Angelman syndrome. Am J Hum Genet 1999; 65: 1-6.

39 Lossie AC, Whitney MM, Amidon D et al: Distinct phenotypes distinguish the molecular classes of Angelman syndrome. $J$ Med Genet 2001; 38: 834-845.

40 Horsthemke B, Wagstaff J: Mechanisms of imprinting of the Prader-Willi/Angelman region. Am J Med Genet A 2008; 146A: 2041-2052.

41 Stalker HJ, Williams CA: Genetic counseling in Angelman syndrome: the challenges of multiple causes. Am J Med Genet 1998; 77: 54-59.

42 Kokkonen H, Leisti J: An unexpected recurrence of Angelman syndrome suggestive of maternal germ-line mosaicism of del(15)(q11q13) in a Finnish family. Hum Genet 2000; 107: $83-85$.

43 Buiting K, Barnicoat A, Lich C, Pembrey M, Malcolm S, Horsthemke B: Disruption of the bipartite imprinting center in a family with Angelman syndrome. Am J Hum Genet 2001; 68: $1290-1294$

44 Bürger J, Buiting K, Dittrich B et al: Different mechanisms and recurrence risks of imprinting defects in Angelman syndrome. Am J Hum Genet 1997; 61: 88-93.

45 Malzac P, Webber H, Moncla A et al: Mutation analysis of UBE3A in Angelman syndrome patients. Am J Hum Genet 1998; 62: 1353-1360.

\section{Clinical features of $\mathbf{A} \mathbf{S}^{1}$}

\section{A. Consistent features $(100 \%)$}

- Developmental delay, functionally severe.

- Movement or balance disorder, usually ataxia of gait, and/or tremulous movement of the limbs. Movement disorder can be mild. May not seem as frank ataxia but can be forward lurching, unsteadiness, clumsiness, or quick, jerky motions.

- Behavioural uniqueness: any combination of frequent laughter/smiling; apparent happy demeanor; easily excitable personality, often with uplifted hand-flapping movements, or waving movements; hypermotoric behaviour.

- Speech impairment, none or minimal use of words; receptive and non-verbal communication skills higher than verbal ones.

\section{B. Frequent features (more than $80 \%$ )}

- Delayed, disproportionate growth in head circumference, usually resulting in microcephaly $\left(<\_2\right.$ SD of 
normal OFC) by age 2 years. Microcephaly is more pronounced in those with 15q11.2-q13 deletions.

- Seizures, onset usually $<3$ years of age. Seizure severity usually decreases with age but the seizure disorder lasts throughout adulthood.

- Abnormal EEG, with a characteristic pattern of large amplitude slow-spike waves. The EEG abnormalities can occur in the first 2 years of life and can precede clinical features, and are often not correlated to clinical seizure events.

C. Associated features (20-80\%)

- Flat occiput

- Occipital groove

- Protruding tongue

- Tongue thrusting, suck/swallowing disorders

- Feeding problems and/or truncal hypotonia during infancy

- Prognathia
- Wide mouth, wide-spaced teeth

- Frequent drooling

- Excessive chewing/mouthing behaviours

- Strabismus

- Hypopigmented skin, light hair and eye colour compared to family, seen only in deletion cases.

- Hyperactive lower extremity deep tendon reflexes

- Uplifted, flexed arm position especially during ambulation

- Wide-based gait with pronated or valgus-positioned ankles

- Increased sensitivity to heat

- Abnormal sleep-wake cycles and diminished need for sleep

- Attraction to/fascination with water; fascination with crinkly items such as certain papers and plastics

- Abnormal food-related behaviours

- Obesity (in the older child)

- Scoliosis

- Constipation 